\title{
Formalized Knowledge of Construction Sequencing for Visual Monitoring of Work-In-Progress via Incomplete Point Clouds and Low-LoD 4D BIMs
}

\author{
Kevin K. Han ${ }^{\mathrm{a}, *}$, David Cline ${ }^{\mathrm{b}}$, Mani Golparvar-Fard ${ }^{\mathrm{c}, 1}$ \\ ${ }^{a}$ PhD Candidate, Department of Civil and Environmental Engineering, University of Illinois at Urbana-Champaign, Urbana, IL \\ ${ }^{b}$ MS Student, Via Department of Civil and Environmental Engineering, Virginia Tech, Blacksburg, VA \\ ${ }^{c}$ Assistant Professor and NCSA Faculty Fellow, Department of Civil and Environmental Engineering, and Department of \\ Computer Science, University of Illinois at Urbana-Champaign, Urbana, IL
}

\begin{abstract}
Background \& Problem Statement: Over the last few years, new methods that detect construction progress deviations by comparing laser scanning or image-based point clouds with 4D BIM are developed. To create complete as-built models, these methods require the visual sensors to have proper line-of-sight and fieldof-view to building elements. For reporting progress deviations, they also require Building Information Modeling (BIM) and schedule Work-Breakdown-Structure (WBS) with high Level of Development (LoD). While certain logics behind sequences of construction activities can augment 4D BIM with lower LoDs to support making inferences about states of progress under limited visibility, their application in visual monitoring systems has not been explored. Objective: To address this, this paper formalizes an ontology that models construction sequencing rationale such as physical relationships among components. It also presents a classification mechanism that integrates this ontology with BIM to infer states of progress for partially and fully occluded components. Validation: The ontology and classification mechanism are validated using a Charrette test and by presenting their application together with BIM and as-built data on real-world projects. Conclusion: The results demonstrate the effectiveness and generality of the proposed ontology. It also illustrates how the classification mechanism augments 4D BIM at lower LoDs and WBS to enable visual progress assessment for partially and fully occluded BIM elements and provide detailed operational-level progress information.
\end{abstract}

Keywords: Sequencing Knowledge, Visual Construction Monitoring, Building Information Modeling

\section{Introduction}

Today, time-lapse, close range, or aerial site images and laser scanners are commonly used for producing as-built 3D point clouds for construction progress monitoring. [1]. Once collected, as-built information is compared against as-planned 4D Building Information Models (BIM) to identify, analyze, and visualize progress deviations. The output -typically a color-coded BIM- is used in coordination processes for quick and accurate assessment of work-in-progress (WIP) and root-cause analysis on performance deviations. To streamline the current workflows, there have been research topics [2-9] on automating part of this cycle

\footnotetext{
${ }^{*}$ Corresponding author

Email addresses: kookin2@illinois.edu (Kevin K. Han), mgolpar@illinois .edu (Mani Golparvar-Fard)

${ }^{1}$ Tel: +1 2173005226
} 
which is highlighted in Figure 1. The underlying principles for analyzing progress deviations roughly fall into two categories:

1) Methods that reason about states of construction progress by comparing as-built point clouds with $4 D$ BIMs - These methods use 3D geometry features to compare actual and expected states of work-inprogress and identify deviations. Based on scene visibility and occupancy in 3D, these methods compare laser scanned point clouds [8-12] or image-based point clouds [6, 13-15] with BIM for automated tracking of progress deviations. For instance, Turkan et al. [9] and Kim et al. [11] developed progress detection methods for structural elements, Mechanical/ Electrical/ Plumbing installments, and secondary and temporary components.

2) Methods that infer states of progress by analyzing appearances of the BIM elements in $2 D$ imagesMethods such as $[2-5,13,16-18,18-22]$ register time-lapsed images, taken from fixed or pan-tilt-zoom camera with BIM to enable as-built vs. as-planned comparisons. Han and Golparvar-Fard [7] register closerange images with BIM through Structure-from-Motion ( $\mathrm{SfM}$ ) procedures. Then, they apply 2D material recognition techniques to identify appearance features, compare actual and expected progress, and identify deviations. The classification on elements appearances (e.g. concrete vs. formwork) infers their most updated states of progress.

[Figure 1 about here.]

While significant improvements have been made, complete and accurate comparison of as-built visual data with 4D BIM still faces a number of challenges:

1) Lack of details in as-planned BIM: At the pre-construction phase of many projects, the level of detail in BIM typically do not capture operation-level details (e.g., formwork, reinforcement, and waterproofing panels for a concrete wall) and therefore, these models are not sufficient for monitoring operationlevel activities. This level of detail corresponds to Level of Development (LoD) 300 or 400. LoD describes standardized information levels in numbers, such as 100, 200,300, 250, 400, and 500 - a higher number indicates a higher level of detail [23]. The operation-level details correspond to LoD 400 to 500. It is not common to see these operation-level details in typical projects, although the authors have observed a few projects with these details. Here is an example to illustrate the effect of lack of details in as-planned BIM. Consider a scenario in which progress on construction of a concrete foundation wall is complete and waterproofing panels are being attached to the foundation walls. A progress monitoring method should leverage visual data from this element -which in this case will depict the waterproofing panels- to compare against its BIM element. However, a BIM without operation-level detail will most likely not contain waterproofing panels as an unique element or even as a layer to the foundation element. Hence, assigning a progress measure becomes a challenge.

2) High-level work breakdown structure (WBS) in construction schedules: For many projects, detailed WBS in construction schedules is not always available. For example, an activity such as "Form/Rebar/ Pour/Strip (FRPS) Concrete Foundation Walls" in a contractor-level schedule will not differentiate a subactivity from the others. Integrating such activity into a 4D BIM does not provide any information on when each "foundation wall" element will be constructed on the site. Figure 2 illustrates some of these limitations where operation-level details need to be tracked, while they are not available in BIM or WBS.

3) Static and dynamic occlusions and incomplete data collection: Various objects can block a visual sensor's line-of-sight. For example, fixed objects (i.e., building elements) cause static occlusions and moving objects (e.g., equipment, workers, and temporary structures) cause dynamic occlusions. Moreover, access to the site under construction is often restricted, resulting in certain areas not being scanned. While unmanned aerial vehicles (UAV) equipped with cameras [24, 25] can improve the data collection, 
and model-based reconstruction methods [26] can improve success and accuracy of BIM-vs.-image registration, in most cases partial or no visibility affects the accuracy of both geometry- and appearance-based methods for inferring progress. Figure 3 illustrates occlusions and different levels of visibility during monitoring data collection. Without taking steps to increase access to blocked areas, alleviating the situation is difficult, absorbs time and resources, and ultimately minimizes the value of automated monitoring. Even if such information is available, monitoring progress for hundreds of elements under these conditions is a challenge.

[Figure 2 about here.]

To frequently compare incomplete and partially/fully occluded as-built visual data against a low LoD as-planned model and schedule without operation-level activities, a progress detector that understands and reasons about common sequences of construction operations is needed. For partially or fully occluded building elements, formalizing the relationships or constraints that govern how these elements are connected to visible elements (e.g. physical relationships, trade interactions, path interference, and code regulations) can help infer their states of progress from the states of related and visible elements. Availability of such formalized knowledge of sequencing in form of an ontology can also compensate for lack of details in BIM or WBS and help infer progress at operation-level. Figure 4 shows how reasoning mechanisms based on formalized sequencing knowledge can improve BIM-driven visual monitoring methods.

[Figure 3 about here.]

[Figure 4 about here.]

To address these needs, this paper builds on classic works on formalizing construction sequencing knowledge and presents 1) an ontology that models construction sequencing rationale necessary for progress monitoring at the operation level, 2) a "classification" mechanism for inferring states of progress based on states of other relevant/visible elements and the sequencing rationale which has been explicitly represented using the proposed ontology, and 3) a formal process that integrates the classification mechanism and ontology with BIM to support reasoning and detailed reporting about states of construction progress when the collected data is incomplete, WBS is at high-level or when BIM is not detailed. In this paper, the investigations and experiments performed to develop each formalization are described. The power and generality of these formalizations are also validated by seeking structured feedbacks through Charette test cases from Architecture/Engineering/Construction (AEC) practitioners involved in the design, construction, and management phases of construction projects, and also using prototype software on data from real-world construction projects.

[Figure 5 about here.]

\section{Motivating Construction Scenarios}

To better illustrate the need for reasoning states of construction progress under limited visibility, lowLoD BIM, and high-level WBS, this section discusses the existing daily photo collections, 3D point cloud modeling, and 4D BIM from three construction projects. They are three mid-size buildings: a student dining facility (SD) and two student residence halls (RH) (Figure 5). The SD structure is comprised of steel for the gravity and lateral systems and a composite floor system. The foundation system is a mixture of continuous concrete footings under walls and spread footings under the steel columns. The structural system for RH is 
a reinforced concrete frame with masonry and curtain wall exterior. BIMs for these projects are LoD300. WBS is also at high-level and does not contain enough information to enable operation-level tracking of construction progress. Site images were also collected by superintendents and field engineers on a daily basis. These images exhibit many cases of partially and fully occluded elements.

Using an image-based 3D reconstruction technique [7], a number of 3D point cloud models were generated for several weeks and these models were brought into alignment with BIMs. These images have limited visibility to many elements. Therefore direct reasoning about their progress is a challenge. Figure 6 shows an example of full occlusion from one of the datasets from the RH project. It shows (a) an image-based 3D point cloud, (b) an image taken from the same viewpoint as in (a) with a warped field-of-view, (c) a transparent BIM superimposed over the point cloud and seen through the image, and (d) a snapshot of a 4D BIM from the same viewpoint. Here, the visibility to a concrete footing element is fully occluded from all 160 images of this dataset, and direct reasoning about a state of progress for this element is not possible. Nevertheless, as shown in Figure 6c, a column that is supported by this footing is partially visible and its state of progress can be inferred from the image and the point cloud. This supported by constraint between the elements implies that the state of progress in construction of the footing should be "complete" as well.

[Figure 6 about here.]

[Figure 7 about here.]

[Figure 8 about here.]

Another example is provided in Figure 7 from the SD project where a concrete wall is covered by by waterproofing panels. This covered by constraint between the elements can support inference on states of construction progress. If the progress detector can not directly infer the state of progress from the partly visible surface, then this covered by constraint can imply that the state of construction progress for the partly visible should be "complete". Here, the formal knowledge of sequencing is not only important for reasoning progress from the visible parts, but also to improve the underlying BIM that may not have a layer associated with waterproofing for the element. Hence, an appearance-based progress detector may not consider recognition of waterproofing panels, and may result in misclassification on the state of progress. Figure 8 also shows another example. In this figure, the attached to constraint between a foundation wall and columns can infer the state of the progress for the columns that are fully occluded from the visible foundation wall.

In summary, above cases clearly exemplify how the inherent relationship between the rationale of the constraints and states of progress help with progress monitoring. After all, field engineers also distinguish precedence relationship between operations as different types of specific constraints (e.g. supported by and covered by) and use that knowledge to infer states of progress in cases of having fully/partially occluded elements or BIM and WBS that are not detailed. The goal of this research thus is to make this domain knowledge and reasoning mechanism on construction sequencing explicit, with the overall objective of supporting inference of progress for visual detection methods that need to constantly deal with visibility issues and lack of detailed planned information. The following section breaks down this goal into specific objectives in detail.

\section{Research Objectives}

The main objective of this research is to formalize a representation of construction sequencing rationale that supports visual progress detection methods to reason about states of progress under limited to no visibility and improve accuracy of progress monitoring for less detailed BIM and WBS. This requires designing 
a taxonomy that categorizes individual constraints and models them in a way that enables visual progress detectors to leverage the descriptions to infer states of progress. Hence, this paper contributes to automated progress monitoring methods by extending formal classifications and providing more detailed information about relationship among BIM elements and schedule WBS to support progress inference.

The second goal of this research is to integrate this formalizing mechanism into vision-based progress monitoring (visual detection methods) for querying geometry and connection information in BIM. The proposed reasoning mechanism, as an integrated project monitoring system that tracks project information and potentially can be automated and can enhance the project monitoring system using visual data and querying information from BIM. This progress monitoring system will automatically infer states of progress, where the rationale of operation sequences has been explicitly described using the formalized representation of construction sequencing rationale. The authors acknowledge that used ontology is mainly for categorization of relations and it does not use the common components of ontologies in information science. The Industry Foundation Class (IFC) schema allows such integration and the relevant concepts are discussed in Section 4.2. The full integration, however, is not a scope of this paper and is left for future research. Instead, the presented mechanism is validated based on hypothetical case studies on real-world projects where states of progress for non-visible elements are inferred by the formalized sequencing ontology. The impact of the ontology on the accuracy of a vision-based progress detection and the relevant findings are discussed in Section 6.3.

\section{Research Methodology for Formalizing Construction Sequencing}

In this paper, the multi-step iterative methodology of Gruninger and Fox [27] is followed to develop and test the proposed ontology and reasoning mechanism. The multi-step iterative process is divided into four distinct parts: 1) reviewing the motivating scenarios with the intended solutions and relevant literature so that the ontology can be structured in a way to answer the problem rationally, 2) development of the supporting ontology, 3) defining the terminology and constraints of the ontology, and 4) validating completeness and effectiveness of the ontology.

This section focuses on the developed ontology and the corresponding attributes, classes and the relations between them. The classes of the ontology are established using the informal competency questions as a guide. The overall process of developing the required ontology is presented in Figure 9. For every question there should exist a class which can be used to answer the question. If the question cannot be answered, either more classes should be added or current ones should be divided into more distinct classes. During the defining process (i.e., yellow boxes in Figure 9), if classes are created without corresponding competency questions, the competency questions may need to be reviewed or the scope of the ontology should be changed. The competency questions are further refined before progressing to the next step. The formal competency questions are used to evaluate the ontology and whether or not it addresses the scenarios for which it was created. The formal competency questions for this paper were mostly related to how elements are physically related to one another. An example questions is "How is a steel column physically related to a steel beam?"

The next step is defining the terminology and constraints of the ontology known as axioms. This step is often the most difficult but the competency questions are useful to guide the process. The axioms are part of the final validation process. Therefore, if the axioms do not help answer the competency questions, a revision is required. The final step is a validation step to test for completeness as well as other metrics presented in Section 5. The method on how this ontology was validated is outlined further in the validation section. 


\subsection{Formalizing knowledge of construction sequencing}

Since 1970s, formalized knowledge of construction sequencing has been the center of research in knowledge-based systems for automated construction planning and scheduling [28-32]. Most relevant study to this paper is Echeverry et al. [32], which classified activities in construction schedules. They categorized activity sequencing into four groups: physical relationship, trade interaction, path interference, and code regulations. Physical relationship constraints (i.e., supported by, covered by, and embedded in) influence the sequencing of activities. In addition, these constraints can exhibit a degree of flexibility since construction is not a set process and variations exist.

Koo et al. [33] describe these constraints and extend these ideas by assigning each constraint an enabling or impeding role and flexibility. The focus was primarily on automated generation and revision of project schedules. Thus, the flexibility described how strong the constraints influence the related construction tasks and whether it is possible to use alternative methods to complete a construction task. These constraints have been adapted for use in automated re-sequencing and revision of construction schedule when a delay impacts the critical path of the schedule and a new schedule must be created [33, 34]. Rescheduling is difficult since it requires understanding of 1) hard logics among activities (i.e., the way elements are physically constructed) and 2) soft logics among activities (i.e., only so many workers may occupy one space or there is limited labor supply). A classification mechanism, that describes logic schedulers to use sequence activities in certain ways, allows faster and more accurate rescheduling in the event of a delay.

These previous works only focus on planning and scheduling, do not consider a model-driven approach to planning or production monitoring, and do not validate the ontologies and logics presented in their work. Also to the best of the authors' knowledge, no mechanism has been built on such ontologies to support 1) reasoning about construction progress in a model-driven approach, 2) cases where BIM and WBS exhibit low level of details, and 3) cases where visibility are partially or fully limited. There is a great synergy between vision-based progress detection and a reasoning mechanism that can build on such ontologies.

Hence, the key contributions of this paper are 1) creating a new reasoning mechanism that applies such sequencing ontology to model-driven vision based methods for progress monitoring under low visibilities and cases where the underlying BIM and WBS are not detailed, 2) validating the proposed ontology for reasoning about construction progress, considering the implications to quality control, and 3) applying the reasoning mechanism to model-driven construction progress monitoring with 4D BIM and image-based 3D point clouds. The proposed ontology is designed for future revisions and editions based on the needs of the visual progress detectors. As discussed previously, Figure 4 illustrates how the developed ontology, that is used as a reasoning mechanism, is incorporated into model-driven vision-based progress monitoring methods.

The definition of each class is important along with attributes. A class may start with several characteristics that make it unique but through utilization it may be deemed necessary to split the class into separate sub-classes:

Connected to- Elements are related physically at a point or along one face. This class has two subclasses to differentiate between connections in the vertical and horizontal directions.

- Attached to: A structural connection among elements which provide support in the lateral direction and may in the gravity direction as well. This connection type is closely related to the supported by class and found primarily in the lateral system of a building which is designed to resist movement in the horizontal direction. Examples include steel cross bracing in a steel building and concrete floor systems which are connected to beams and columns (Figure 10a). 
- Supported by: A structural connection among elements which act in the gravity direction. Nearly every connection in the structural system of a building can be considered as a supported by relationship. Beam-to-column connections and foundations supporting masonry walls are the most prevalent. More specific examples are structures with cast in place (CIP) columns that are often connected to and supported by structural concrete foundation walls. These CIP columns form a T-shape from a plan view and are modeled as separate elements (Figure 10b).

Embedded in- An element permanently inside of another. This class has an attribute of structural. Depending on the type of connection, the relationship may be given a structural or non-structural rating.

- Structural: An element permanently inside another element which provides structural capacity between the two. Removing the embedded element would destroy the structural capacity of the embedded element and the embedment material. Many structural embedments are found within concrete because nearly all concrete works require reinforcement to provide tension capacity. An example is when attaching steel columns to a concrete foundation, anchor bolts are cast into the concrete during placement (Figure 10c).

- Non-structural: An element permanently inside another element not providing structural capacity to either element. Removing the embedded element would damage the embedded element. Utilities passing through either a concrete floor slab or a concrete foundation wall are common examples of this instance. For instance, underground utilities (often located under existing grade) require protrusion through the foundation wall. These elements are non-structural and proper access must be provided during the casting process (Figure 10d).

Enclosed by- An element or system of elements contained within an open space of another element or building system. The connections are at discrete points. The contained element cannot be removed as one unit from the space but can be disassembled and removed without damage to either. Mechanical equipment enclosed by a surrounding room is a common example. Electrical wiring inside a conduit is another case but should not be confused with embedded in since the attachment is not permanent. An example is an elevator in a low rise building which may be hydraulically operated and requires a large subgrade hole for the shaft to recess into. This is placed during foundation work before surrounding walls reduce working space (Figure 10e).

Covered by- An element or system of elements attached at one or more faces. This connection is not structural. The connection among the elements is usually completely obscured from view by the other. Depending on the method of attachment among the elements, removing the covering element would damage it and may damage the covered element. Figure 10f illustrates a case where a brick facade covering a concrete masonry wall (CMU). The CMU is installed first then followed by the facade on the exterior and often drywall on the inside.

[Figure 10 about here.]

Table 1 summarizes the above classes and provides an example per class. The column labeled "Activity Sequencing" depicts how each class would typically be represented on a bar chart showing the Finish-toStart, Start-to-Start and other relationship which can exist among schedule activities or in this particular case, elements. With the reasoning mechanism integrated with BIM, any progress detectors leveraging visual data (images and point clouds) and BIM can infer an element that is not visible by visual sensors. 
For instance, a relation (e.g., supported by) between a concrete foundation wall and its footing can be used to infer that the footing is completed in case of an occlusion due to backfill. Visual analytics have their own way of dealing with occlusions and this approach will work in addition to further deal with occlusions. This integration with BIM for querying physical relationships among elements is described in the following section.

[Table 1 about here.]

\subsection{Implementation in IFC Representation}

This section presents how the proposed reasoning mechanism can be coded and integrated as part of a model-driven vision-based progress monitoring detection method. The relationships described by the reasoning mechanism can be represented by BIM using the Industry Foundation Classes (IFC) schema [35]. The IFC schema is really important because it has semantic information about various aspects of elements stored in classes. Moreover, the stored information can be queried [36]. Its classes can capture the physical relationships in the proposed ontology. A model-based progress monitoring detector can leverage several classes in IFC, which could be used for inferring the relationships among elements. One of which is the class IfcConnectionGeometry containing subclasses IfcConnectionPointGeometry, IfcConnectionCurveGeometry, and IfcConnectionSurfaceGeometry. They describe how the elements are physically related (i.e. the geometric and topological constraints which describe a physical connection of two objects) and could be queried from IFC in order for inferences to be made. This concept of storing and querying physical relationships allows model-based progress monitoring detectors to leverage the proposed ontology for enhanced performance. Figure 11 shows the structure of IfcConnectionGeometry classes. This paper proposes a structure of the IfcConnectionGeometry class as the IFC class that describes the physical relationship between building elements, bridging the gap between the reasoning mechanism and vision-based progress monitoring methods.

[Figure 11 about here.]

Figure 12 shows the EXPRESS representation of the IfcRelConnectsElements. It provides the generalization of the connectivity types among building elements (e.g. one-to-one, or one-to-many relationships) which could be physical or logical. If the connection has geometric constraints, then the optional relationship, IfcConnectionGeometry (Figure 13), can be used to represent it.

[Figure 12 about here.]

[Figure 13 about here.]

[Table 2 about here.]

\section{Research Validation}

A group of practitioners in the Architecture/Engineering/Construction (AEC) industry were asked to test the validity of the proposed ontology and the classification mechanism. The test method followed a Charrette Test [37] which is intended for software development and has been primarily used to validate development of ontological representations in the AEC community. The validity of the new process is measured by the effectiveness and the repeatability of the process. Effectiveness is measured by how usable the process is not only by the researchers and the intended user but also by those with the most basic 
understanding of the principles behind the process. Another metric for effectiveness is how general the process is and whether it can be applied to a wider range of applications beyond visual progress detection. The repeatability aspect questions whether or not the process can be repeated by different researchers and users under a variety of situations.

To do so, the authors created, developed, and utilized a test. A wide range of responses were collected from 21 professionals, who had more than 360 years of combined experience ranging from one to over 40 years in the industry and are working or have worked at a variety of projects. Table 2 shows a description of the participants and their expertise. The test was divided into two sections each with a specific objective. The first section contained questions where the participants were asked to identify the relationship among different elements commonly found in a building, using the ontology. The second section contained several images from construction sites and the participants were asked to infer the status of construction progress for occluded elements based on elements visible in the image. Table 3 shows a detailed description of the first section of the test. As seen, in Section A of the form based on the developed ontology of physical relationships, the professionals were asked to define the physical relationships among several examples. The order of the elements provided in the example was not important as the relations were symmetric (e.g., the relationship between a Beam and Column was assumed to be the same as a Column and Beam).

[Table 3 about here.]

The purpose of the second section of the test (See Table 4) was to test whether it is reasonable to infer the physical construction progress status of certain elements based on the presence of other elements. Based on the parts of the building visible or indicated in the images that were extracted from the dining and residential hall case studies mentioned previously, the users were asked to infer progress status (complete/incomplete) of several building components. For each image there were three options to choose from: complete, incomplete or not enough information. If the users chose not enough information they were asked to detail why they chose this in the comments section and what information could possibly aid them in determining the status of the occluded element.

[Table 4 about here.]

The first section where participants were asked to use the proposed ontology to define the relationship among elements resulted in participants replicating the authors selection for $73 \%$ of the scenarios. Many of the respondents provided useful comments for their reasoning on each question providing greater insight into their logic. Particularly one of the responds included the following:

“...My assumptions were as follows: (1) I assumed that, if the view of work was occluded by a material that also precluded that the earlier work was no longer accessible, I assumed it was complete. (2) On the other hand, if the view of work was occluded but that work could still be accessed, I assumed that there was not enough information. In short, I assumed that there was no instance in which work was covered and made inaccessible prior to it being completed and $100 \%$ correct. This made sense to me in the context of this test, but may be erroneous in the real-world environment. As we know, concrete still is occasionally poured into forms in which the rebar is not $100 \%$ complete and correct ..."

Based on overall feedbacks and as observed in this particular case, the assumptions used in the development of the ontology made sense, yet one key issue is considerations of construction quality which in this case is proposed to have the same importance of the construction progress. As a result, actual progress 
should not be automatically reported (similar to percent-built-as-planned by Bosché et al. [8]) unless quality of the finished elements is controlled for compliance against plan, and project specifications. Table 5 presents the accuracies of the outcomes of validating the ontology class selection by soliciting feedback from the practitioners.

[Table 5 about here.]

Among all the examples that were provided on Section A of the test, Question 14 as observed in Table 5 received the least level of accuracy (i.e., Concrete Masonry Unit (CMU) - Wall Brick Façade). After clarifying the current answer, majority of the users agreed with the selected ontology class. The second section of the test examines whether it is reasonable to infer the status of elements based on the presence of other related ones. The participants were shown images from constructions sites (as shown in Table 4) and were asked to infer the status of certain elements based on other elements within the same image. This section yielded in participants selecting the authors choice for $65 \%$ of the images. A relatively large portion of inconsistent outcomes were based on responses that stated not enough information. According to many of the interviewees, the only way to truly know states of progress is to see both the project schedule and drawings for the element in question, which can be addressed by percent-built-as-planned [8]. The following is an example of one of such responses:

"...In general, there is insufficient information provided in the photographs to make a determination based solely on the information shown in the photographs. For example, Photo 1 shows a beam that is supporting a number of joists, yet the ends of the beam are not visible. The photo asks for a comment on the status of the columns supporting the beam. Given that the steel framing appears to be advanced and complete, the immediate conclusion is that the columns also are complete. However, the beam could be supported be temporary columns at the ends, the anchor bolts for the columns may not be installed, nuts could be missing and column bracing could not be in place. Until every aspect of the column is completed, it would be negligent to indicate otherwise and the status cannot be confirmed from the photo ..."

Similarly, the response is in support of formation of the proposed ontology, nonetheless construction quality is required to be inspected simultaneously with construction physical progress. Another interesting issue which resulted from the test was the requirement of liability for acceptance of construction progress:

“...From a professional liability perspective, it would be difficult to convince a practitioner to sign off on completion of an element based on the information shown in the photographs alone. Some parameters of acceptance would have to be established and accepted by all involved for this to happen. For example, there should be constant inspection at the site ensuring that the construction is performed in accordance with the plans and specifications. Given that this is occurring, it is reasonable to infer from Photo 3 that the footing is completed and in place. However, if the fact that the inspection is reliably occurring is not an accepted starting point for the evaluation, then the photo cannot be used to determine if the footing is complete. Photos can be used to reliable state that items are incomplete ..."

In this case, it seems perhaps the ontology can support automated detection of behind schedule elements without a proper control on the quality. Automated progress detection on challenging scenarios perhaps be reported more carefully, distinguishing confident and non-confident assessments. Overall, the authors intent for the participants was to assume based on their knowledge of construction sequencing what could be 
inferred regarding the status of the target element using information in the image. By carefully studying the comments, majority of the responses are in accordance with the proposed ontology. Those responses not in full harmony with the ground truth results of the test are mainly requiring either quality to be checked simultaneously or only behind-schedule elements to be reported to minimize the liability of accepting finished elements with lower than planned quality. Overall, the logic is that a visual based system would only have the information gathered from the data collection process and may or may not have information from a digital model or schedule.

\section{Discussions on the Outcome of the Developed Ontology}

\subsection{Overall Developed Ontological Model}

Figure 14 summarizes the ontology presented in this paper and depicts the hierarchy among the classes. Each box represents a class of the ontology and a circle denotes an attribute of the associated class. For example the Embedded In class can have either a structural or non-structural attribute associated with it. The figure also outlines how the physical relationships relate to other relationships such as code regulations and trade interactions.

[Figure 14 about here.]

\subsection{Creating a Roadmap based on the Outcome of the Test}

The ontological model in Figure 14 incorporates all the validated components of the proposed physical relationship, in addition to Path Interference, Code Regulation, and Trade Interaction. Adding these relationships to IFC-based BIM models require a detailed WBS to be developed and incorporated within a 4D (3D + time) baseline model. Such detailed relationship ontology can provide the required baseline for a comprehensive automated assessment of construction progress. It, however, requires the visual monitoring systems to be further developed to incorporate tracking of construction resources (equipment, labor and material) in order to build upon such reasoning for detection of progress in cases of partial or full occlusions. In addition, based on the feedbacks from the test, the ontology model needs to be further developed to use project specification to verify and reason about quality of the completed components. Without a proper sensing of all the components and reasoning about quality of the finished components, only detection of behind-schedule components would be possible and on-schedule or ahead-of-schedule activities would remain susceptible to quality inspection issues. The authors (and other researchers [6-15]) envision that this research will be extended to include reasoning on construction quality to ultimately lead to a more streamlined construction performance assessment process. In addition, non-physical relationships can also be added to the ontology to enable data from video based sensors to be added to automated progress detection systems. For instance, if a mechanical work is under construction in a space, the structural work should have been completed. This reasoning can be described by non-physical relationships such as trade interaction and work space.

The authors also want to emphasize that incorporating the reasoning mechanism can enhance visionbased progress detection in case of low visibility - even when there is a highly detailed BIM. The reasoning mechanism can detect progress at the operation-level activities in both cases of when such activities are and are not reflected in WBS and BIM. Our intent is not to replace high level of detail in WBS and BIM.

\subsection{Enhanced Vision-based Progress Monitoring}

\section{1) Limited Visibility}

To separate the impact of the advancement due to the ontology-based reasoning mechanism from accuracy of visual progress detectors, a full integration of the proposed ontology into vision-based progress 
monitoring detectors is not considered. Instead, it is assumed that the visual progress detector has an ideal performance and the impact of the ontology and the reasoning mechanism on improving the performance of the detector on several hypothetical cases are discussed. The cases are two time instances of the second RH project - denoted as $R H_{O c t}$ and $R H_{D e c}$ for Oct 22, 2014 and Dec 03, 2014, respectively. 1,456 and 1,295 images of 12-megapixel are taken around the building. The same approach as Han and Golparvar-Fard [7] and Golparvar-Fard et al. $[6,17]$ is used for image-based 3D reconstruction and registration with a BIM.

Figure 15 illustrates visibility issues for these two cases - limited visibilities due to 1) shadow casted by recently placed slab and its supporting posts $\left(R H_{O c t}\right)$, and 2$)$ temporarily structure and plastic sheets installed for protection against cold weather in winter $\left(R H_{D e c}\right)$. The first and second columns of the figure correspond to $R H_{O c t}$ and $R H_{D e c}$, respectively. The top row shows a point cloud and an image overlaid for each dataset and the lower row shows the registered BIM from the same camera's field-of-view. The yellow boxes show limited visibilities and their correspondences in the BIM. As can be seen, some of the concrete columns in $R H_{O c t}$ are partially occluded due to a shadow but can be inferred its completeness by their physical relationship with the slab above (slab is supported by columns). Similarly for $R H_{D e c}$, the columns hidden behind the plastic sheet are not visible but their existence can be inferred by their physical relationship with the slab above, if the slab is visible and already detected in any of the images used. The existence of the slab guarantees the existence of its supporting columns.

For both cases, the total numbers of elements, numbers of non-visible elements, and percentages of those non-visible elements are presented in Table 6. The number of non-visible elements in this table only accounts for the elements that can be inferred by the physical relationships of the proposed ontology. This assumption allows to study the impact of the proposed ontology on vision-based progress monitoring. As can be seen in the table, the percentages of non-visible elements contributing to the overall accuracy of vision-based progress monitoring can be significant. Since visual detection methods cannot make any inference on non-visible elements, even a method with a high accuracy will always lose this much of percentages on its accuracy. If, however, these elements can be inferred according to the proposed ontology and reasoning mechanism, then the overall accuracy will increase. For $R H_{O c t}$ and $R H_{D e c}$, such vision-based progress monitoring method has no visibility to $5.7 \%$ and $7.5 \%$ of the building elements. Integrating the proposed reasoning mechanism can potentially reason about progress deviations on up to $5.7 \%$ and $7.5 \%$ more elements.

[Figure 15 about here.]

[Table 6 about here.]

\section{2) Level of Development for BIM}

As discussed previously, LoD for BIM is also an important aspect of vision-based progress monitoring. Figure 16 illustrates a case for $R H_{O c t}$ where a 4D BIM element (concrete wall) does not capture operationlevel detail (formwork). In this case, the formalized activity sequences can be used for detecting WIP elements. For instance, if the appearance-based (which is vision-based) method proposed by Han and Golparvar-Fard [7] detects formwork, we can infer that this is a concrete element in progress, inferring it as WIP. This process allows the method to incorporate percent plan complete (PPC), rather than a binary fashion - incomplete or complete. In other words, it can extract operation-level details beyond what is typically provided in WBS of a schedule.

[Figure 16 about here.] 


\section{Conclusion and Future Work}

This paper presents the formalized ontology for construction sequencing together with the classification mechanism to assist vision-based progress monitoring systems with utilizing partial or incomplete as-built information and 4D BIM at low LoDs and less detailed WBS. This research takes a multi-step iterative process beginning with motivating scenarios, which are in turn answered with formal and informal competency questions. The motivating scenarios depict situations where there are not enough or there exist incomplete information regarding the status of elements due to occlusions, lack of proper WBS, and low LoD in BIM. The approach taken by the authors utilizes literature review of previously established ontologies related to construction sequencing and expands for monitoring construction progress. This paper proposes using semantic information contained within the IFC structure to infer the working status of certain elements of a structure based on the presence of related elements linked through the proposed ontology. To aid in both creating and evaluating the ontology, the authors sought help from industry experts. The ontology is integrated into a Charette test and results revealed that $73 \%$ of the scenarios were acceptable by the large pool of participants. Examples of the benefits of the classification mechanism in improving the performance of visual progress detectors were illustrated. Open research challenges, such as incorporating quality aspects in a fully integrated and automated progress monitoring, were also discussed. This work is meant to be a starting point for the ontology. The ontology is intended to be continuously modified as needed and cover more in breadth as well as depth. This continuously developed and improved ontology will be integrated into authors' vision-based automated progress monitoring system for improved performance.

\section{Acknowledgment}

The authors would like to thank Turner Construction for providing access to their job sites, in addition to all the individuals who participated in the survey for this report who provided numerous constructive comments to improve it. This work is funded in part by the National Science Foundation (NSF)'s grant CMMI-1360562 and the National Center for Supercomputing Applications (NCSA)s Institute for Advanced Computing Applications and Technologies Fellows program. Any opinions, findings, conclusions or recommendations presented in this paper are those of the authors and do not reflect the views of NSF, NCSA, Turner Construction or the individuals acknowledged above.

\section{References}

[1] J. Yang, M.-W. Park, P. A. Vela, M. Golparvar-Fard, Construction performance monitoring via still images, time-lapse photos, and video streams: Now, tomorrow, and the future, Advanced Engineering Informatics (2015).

[2] Y. M. Ibrahim, T. C. Lukins, X. Zhang, E. Trucco, A. P. Kaka, Towards automated progress assessment of workpackage components in construction projects using computer vision, Advanced Engineering Informatics 23 (2009) 93-103.

[3] H. Kim, N. Kano, Comparison of construction photograph and vr image in construction progress, Automation in Construction 17 (2008) 137-143.

[4] X. Zhang, N. Bakis, T. C. Lukins, Y. M. Ibrahim, S. Wu, M. Kagioglou, et al., Automating progress measurement of construction projects, Automation in Construction 18 (2009) 294 - 301.

[5] D. Rebolj, N. Čuš Babič, A. Magdič, P. Podbreznik, M. Pšunder, Automated construction activity monitoring system, Advanced Engineering Informatics 22 (2008) 493 - 503.

[6] M. Golparvar-Fard, F. Peña Mora, S. Savarese, Automated progress monitoring using unordered daily construction photographs and ifc-based building information models, Journal of Computing in Civil Engineering (2012) 147.

[7] K. Han, M. Golparvar-Fard, Appearance-based material classification for monitoring of operation-level construction progress using 4d bim and site photologs, Automation in Construction 53 (2015) $44-57$.

[8] F. Bosché, A. Guillemet, Y. Turkan, C. Haas, R. Haas, Tracking the built status of mep works: Assessing the value of a scan-vs-bim system, Journal of Computing in Civil Engineering (2013). 
[9] Y. Turkan, F. Bosché, C. Haas, R. Haas, Tracking Secondary and Temporary Concrete Construction Objects Using 3D Imaging Technologies, pp. 749-756.

[10] F. Bosché, C. T. Haas, B. Akinci, Automated recognition of 3d cad objects in site laser scans for project 3d status visualization and performance control, Journal of Computing in Civil Engineering 23 (2009) 311-318.

[11] C. Kim, H. Son, C. Kim, Automated construction progress measurement using a 4d building information model and 3d data, Automation in Construction 31 (2013) 75 - 82.

[12] F. Bosché, Plane-based registration of construction laser scans with 3d/4d building models, Advanced Engineering Informatics 26 (2012) 90-102.

[13] M. Golparvar-Fard, F. Pena-Mora, S. Savarese, Integrated sequential as-built and as-planned representation with tools in support of decision-making tasks in the aec/fm industry, Journal of Construction Engineering and Management 137 (2011) $1099-1116$.

[14] S. Tuttas, A. Braun, A. Borrmann, U. Stilla, Validation of bim components by photogrammetric point clouds for construction site monitoring, in: ISPRS Annals of the Photogrammetry, Remote Sensing and Spatial Information Sciences, Volume II-3/W4, 2015, Munich, Germany.

[15] B. A. Braun A., Tuttas S., S. U., A concept for automated construction progress monitoring using bim-based geometric constraints and photogrammetric point clouds, in: ITcon Vol. 20, Special Issue ECPPM 2014 - 10th European Conference on Product and Process Modelling, pg. 68-79, Vienna, Austria.

[16] M. Golparvar-Fard, F. Peña Mora, Application of Visualization Techniques for Construction Progress Monitoring, pp. 216223.

[17] M. Golparvar-Fard, F. Peña Mora, S. Savarese, Application of d4ar a 4-dimensional augmented reality model for automating construction progress monitoring data collection, processing and communication, ITcon 14 (2009) 129-153.

[18] T. C. Lukins, E. Trucco, Towards automated visual assessment of progress in construction projects., in: BMVC, pp. 1-10.

[19] C. Kim, B. Kim, H. Kim, 4d $\{\mathrm{CAD}\}$ model updating using image processing-based construction progress monitoring, Automation in Construction 35 (2013) $44-52$.

[20] M. Golparvar-Fard, F. Peña Mora, C. A. Arboleda, S. Lee, Visualization of construction progress monitoring with 4d simulation model overlaid on time-lapsed photographs, Journal of Computing in Civil Engineering 23 (2009) 391-404.

[21] A. Elazouni, O. A. Salem, Progress monitoring of construction projects using pattern recognition techniques, Construction Management and Economics 29 (2011) 355-370.

[22] S. El-Omari, O. Moselhi, Integrating 3d laser scanning and photogrammetry for progress measurement of construction work, Automation in construction 18 (2008) 1-9.

[23] Project Building Information Modeling Protocol Form, AIA Document G202 - 2013, Technical Report MSU-CSE-06-2, American Institute of Architects, Washington, D.C., 2013.

[24] S. Zollmann, C. Hoppe, S. Kluckner, C. Poglitsch, H. Bischof, G. Reitmayr, Augmented reality for construction site monitoring and documentation, Proceedings of the IEEE, Special Issue on Application of Augmented Reality 102 (2014) 137-154.

[25] S. Siebert, J. Teizer, Mobile 3d mapping for surveying earthwork projects using an unmanned aerial vehicle (uav) system, Automation in Construction 41 (2014) $1-14$.

[26] K. Karsch, M. Golparvar-Fard, D. Forsyth, Constructaide: analyzing and visualizing construction sites through photographs and building models, ACM Transactions on Graphics (TOG) 33 (2014) 176.

[27] M. Grninger, M. S. Fox, Methodology for the design and evaluation of ontologies, in: International Joint Conference on Artificial Inteligence (IJCAI95), Workshop on Basic Ontological Issues in Knowledge Sharing.

[28] I. Goldstein, B. Roberts, Nudge: A knowledge-based scheduling system, Proc. 5th Int'l Joint Conference on AI (1977) 257-263.

[29] R. Levitt, J. Kunz, Using knowledge of construction and project management for automated schedule updating, Project Management Journal 16 (1985) 57-76.

[30] D. Navinchandra, D. Sriram, R. Logcher, Ghost: Project network generator, Journal of Computing in Civil Engineering 2 (1988) 239-254.

[31] J. De La Garza, C. Ibbs, Knowledge elicitation study in construction scheduling domain, Journal of Computing in Civil Engineering 4 (1990) 135-153.

[32] D. Echeverry, C. Ibbs, S. Kim, Sequencing knowledge for construction scheduling, Journal of Construction Engineering and Management 117 (1991) 118-130.

[33] B. Koo, M. Fischer, J. Kunz, Formalization of construction sequencing rationale and classification mechanism to support rapid generation of sequencing alternatives, Journal of Computing in Civil Engineering 21 (2007) 423-433.

[34] O. Abudayyeh, Audio/visual information in construction project control, Advances in Engineering Software 28 (1997) 97 101.

[35] buildingSMART International Ltd, Ifc overview summary, 2014. [Online; accessed 22-December-2014].

[36] S. Daum, A. Borrmann, Processing of topological $\{$ BIM $\}$ queries using boundary representation based methods, Advanced 
Engineering Informatics 28 (2014) $272-286$.

565 [37] M. Clayton, J. Kunz, M. Fischer, The charrette test method, CIFE Technical Rep 120 (1998). 


\section{List of Figures}

1 The analytics process for the cycle of construction planning, monitoring, and control via as-built visual data and 4D BIM. . . . . . . . . . . . . . . . . .

2 LoD for operation-level progress: as-planned BIM (top) and corresponding as-built elements; (bottom) . . . . . . . . . . . . . . . . . . . . . . . .

3 (a) Different types of visibility and the expected state of progress based on the line of sight when a superintendent takes a photo; (b) Different levels of element visibility in a site image. 19

4 Incorporating formalized knowledge of sequencing with the reasoning mechanism for modelbased visual progress monitoring methods . . . . . . . . . . . . . . . 20

5 BIM of student dining project (left) and one of the student residence hall projects (right) .

6 The supported by constraint between the visible column and the occluded footing shown in (c) implies that if the observed state of construction for the column is complete, then the state of construction for the footing should be complete as well. . . . . . . . . . . . .

7 The covered by constraint between the waterproofing panels and the occluded foundation wall shown in (c) implies that if the observed state of construction for the panel is complete, then the state of construction for the wall should be complete as well. . . . . . . . . . . .

8 The attached to constraint between the concrete foundation wall and the concrete column shown in (c) implies that if the observed state of construction for the wall is complete, then the state of construction for the column should be complete as well. . . . . . . . . . . . .

9 Ontology development process . . . . . . . . . . . . . . . . . .

10 Examples of the scenarios proposed: (a) Concrete Floor System connected to Beams and Columns; (b) Cast in place columns connected to Foundation Wall; (c) anchor rods embedded in Cast in Place Concrete; (d) sewer Line embedded in Foundation Wall; (e) Enclosed by: Elevator Shaft (hydraulic); and (f) covered by: Concrete Masonry Wall covered by

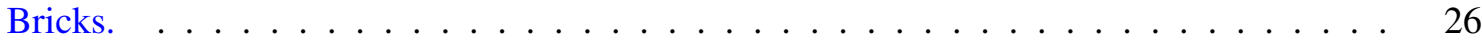

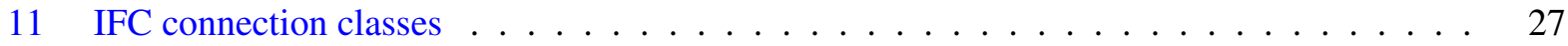

12 EXPRESS representation of IfcRelConnectsElements . . . . . . . . . . . . . . . 28

13 EXPRESS representation of IfcConnectionGeometry . . . . . . . . . . . . . . . . . . . . 29

14 The proposed ontology to support automated progress monitoring . . . . . . . . . . 30

15 Point clouds with overlaid images and registered BIM illustrating limited visibilities: $R H_{O c t}$

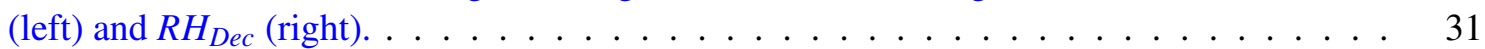

16 Low LoD in BIM: WIP concrete element shown in a point cloud+image and BIM . . . . . 32 


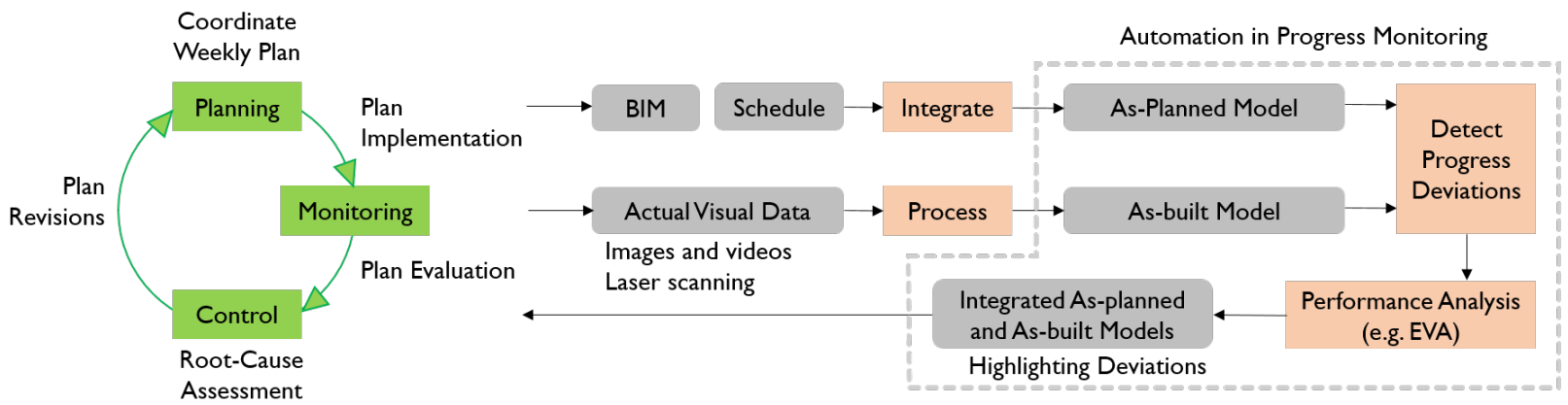

Figure 1: The analytics process for the cycle of construction planning, monitoring, and control via as-built visual data and 4D BIM. 


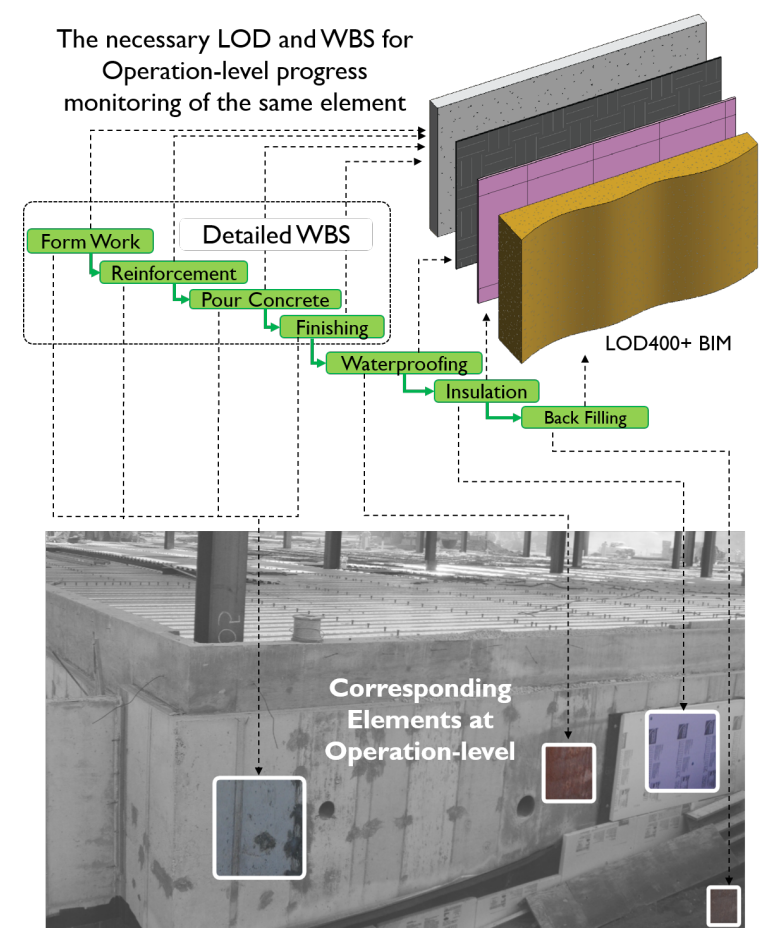

Figure 2: LoD for operation-level progress: as-planned BIM (top) and corresponding as-built elements; (bottom) 


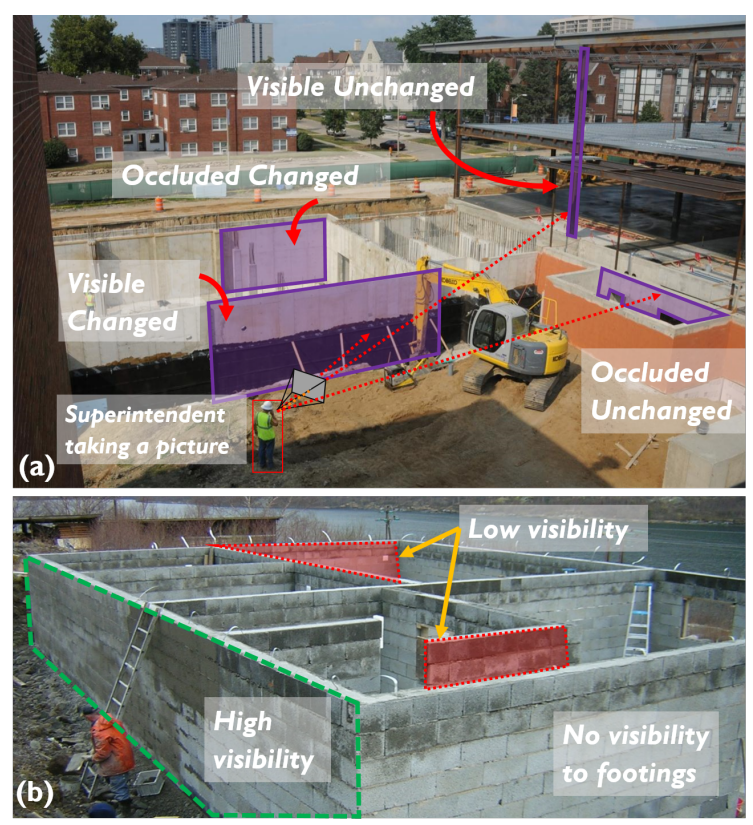

Figure 3: (a) Different types of visibility and the expected state of progress based on the line of sight when a superintendent takes a photo; (b) Different levels of element visibility in a site image. 


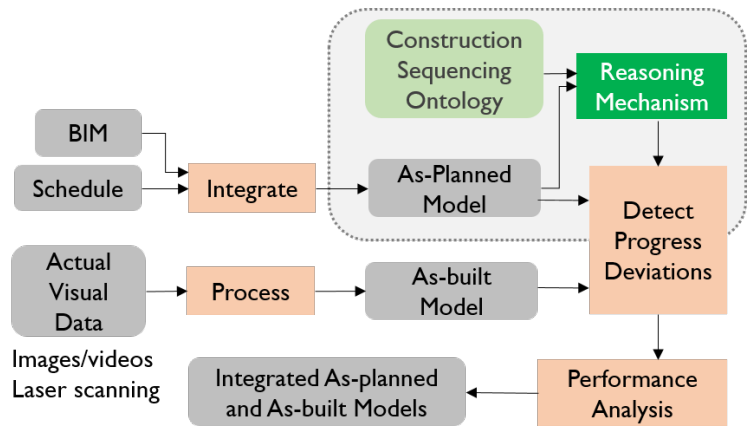

Figure 4: Incorporating formalized knowledge of sequencing with the reasoning mechanism for model-based visual progress monitoring methods 


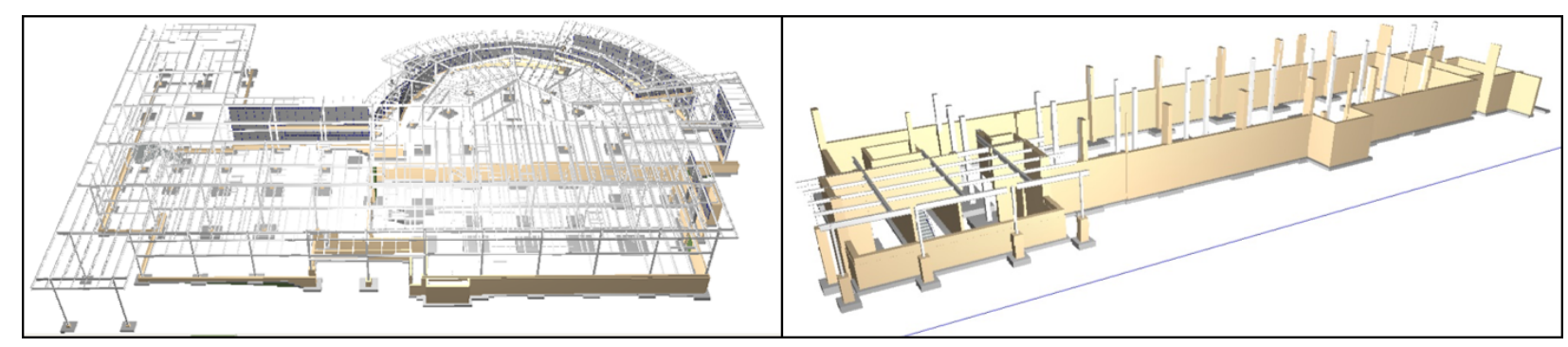

Figure 5: BIM of student dining project (left) and one of the student residence hall projects (right) 


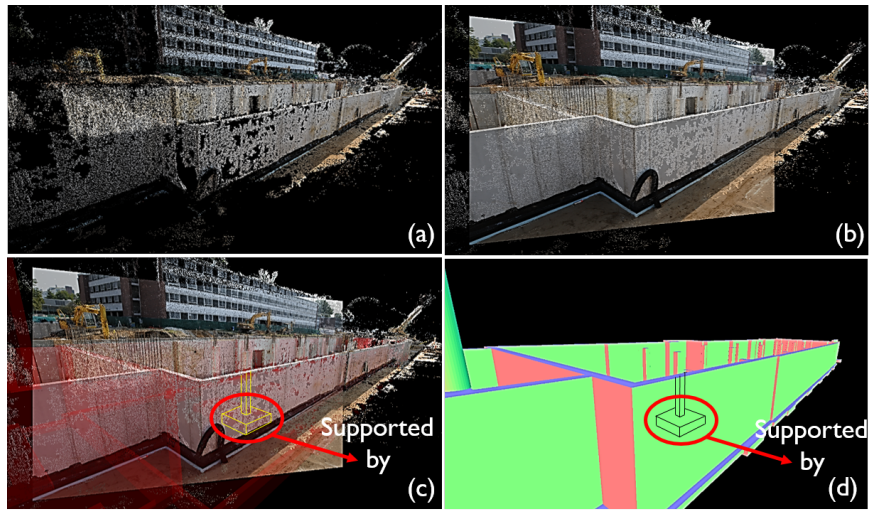

Figure 6: The supported by constraint between the visible column and the occluded footing shown in (c) implies that if the observed state of construction for the column is complete, then the state of construction for the footing should be complete as well. 


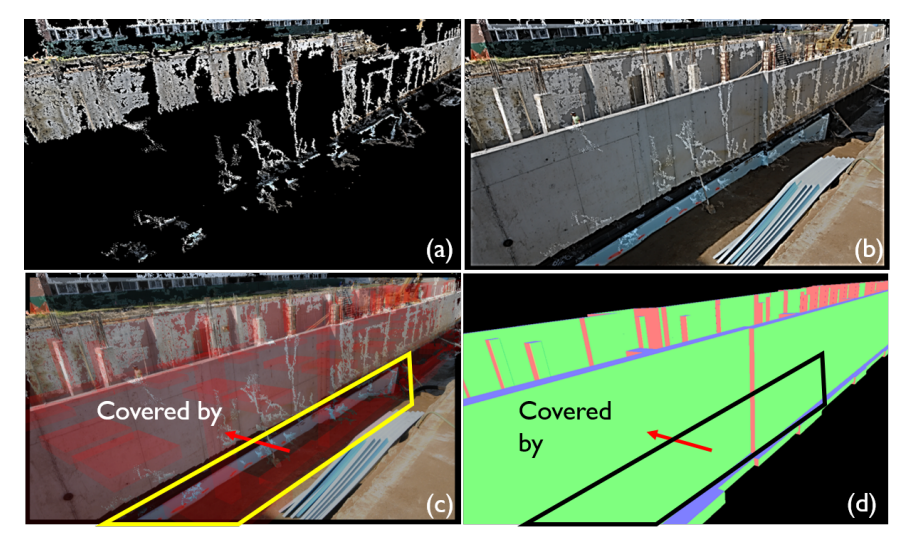

Figure 7: The covered by constraint between the waterproofing panels and the occluded foundation wall shown in (c) implies that if the observed state of construction for the panel is complete, then the state of construction for the wall should be complete as well. 


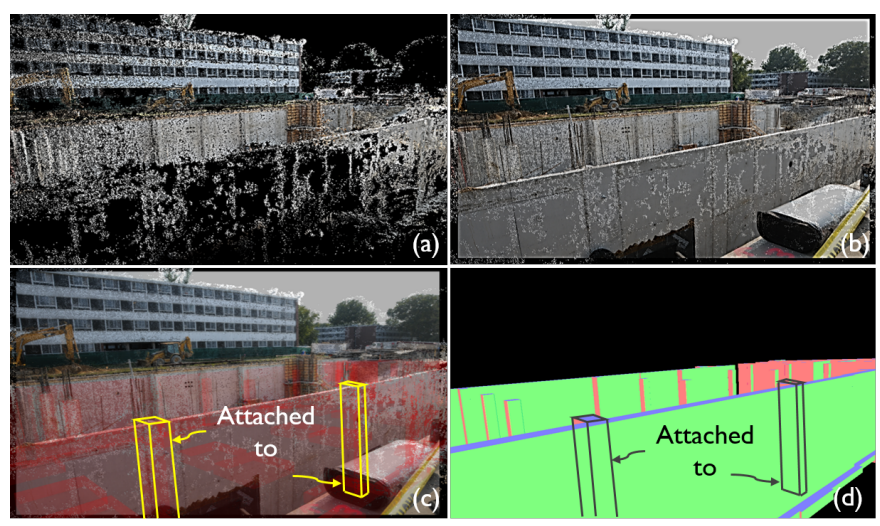

Figure 8: The attached to constraint between the concrete foundation wall and the concrete column shown in (c) implies that if the observed state of construction for the wall is complete, then the state of construction for the column should be complete as well. 


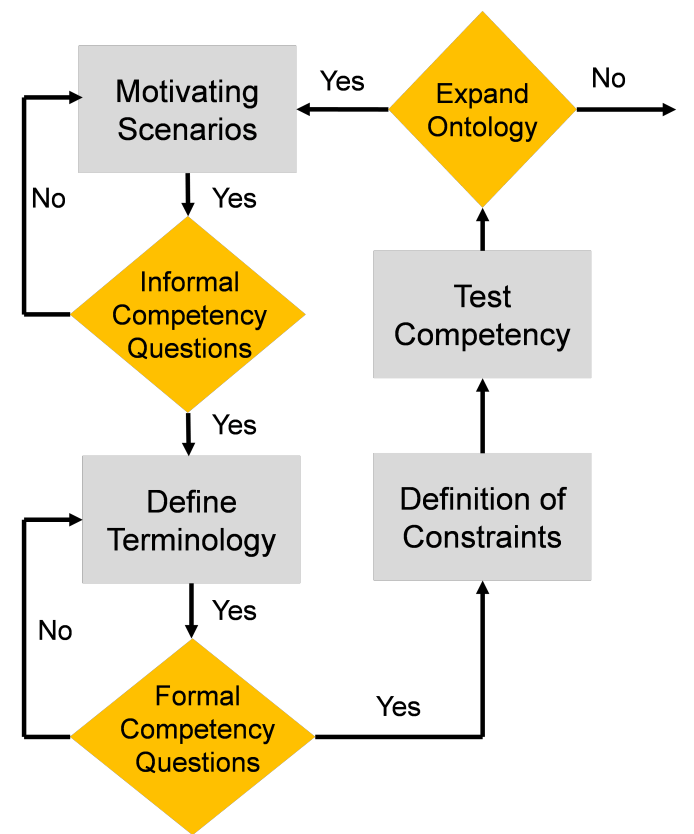

Figure 9: Ontology development process 


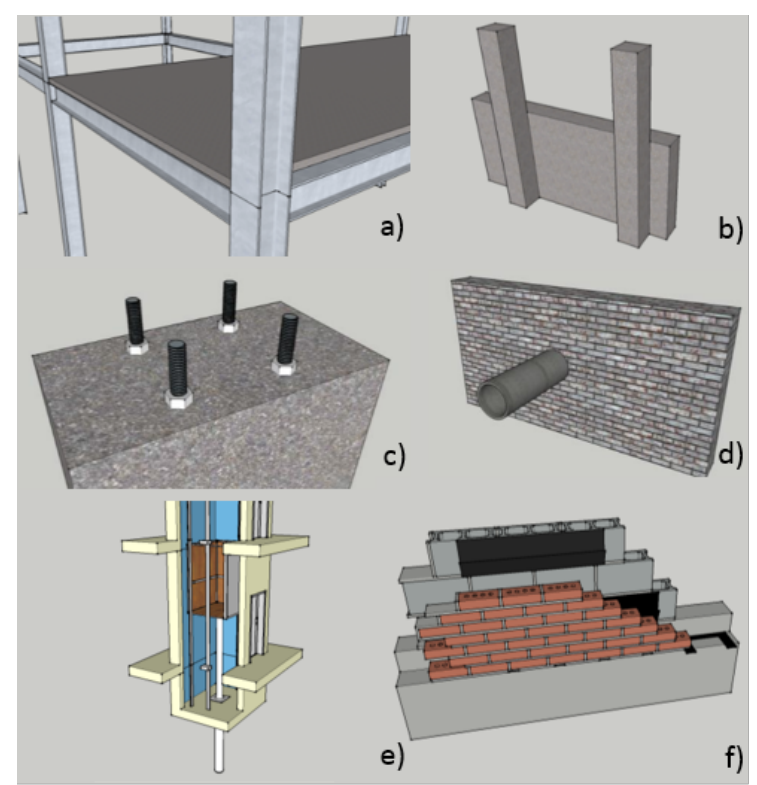

Figure 10: Examples of the scenarios proposed: (a) Concrete Floor System connected to Beams and Columns; (b) Cast in place columns connected to Foundation Wall; (c) anchor rods embedded in Cast in Place Concrete; (d) sewer Line embedded in Foundation Wall; (e) Enclosed by: Elevator Shaft (hydraulic); and (f) covered by: Concrete Masonry Wall covered by Bricks. 
IfcConnectionGeometry

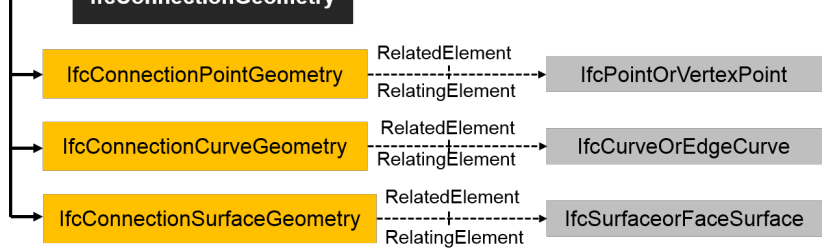

Figure 11: IFC connection classes 


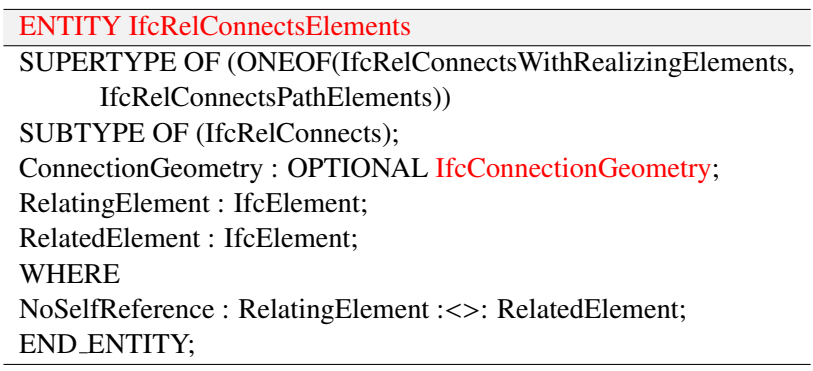

Figure 12: EXPRESS representation of IfcRelConnectsElements 


\begin{tabular}{l}
\hline ENTITY IfcConnectionGeometry \\
\hline ENTITY \\
ABSTRACT SUPERTYPE OF(ONEOF(IfcConnectionPointGeometry, \\
$\quad$ IfcConnectionCurveGeometry, IfcConnectionSurfaceGeometry, \\
IfcConnectionVolumeGeometry)); \\
END_ENTITY; \\
\hline
\end{tabular}

Figure 13: EXPRESS representation of IfcConnectionGeometry 


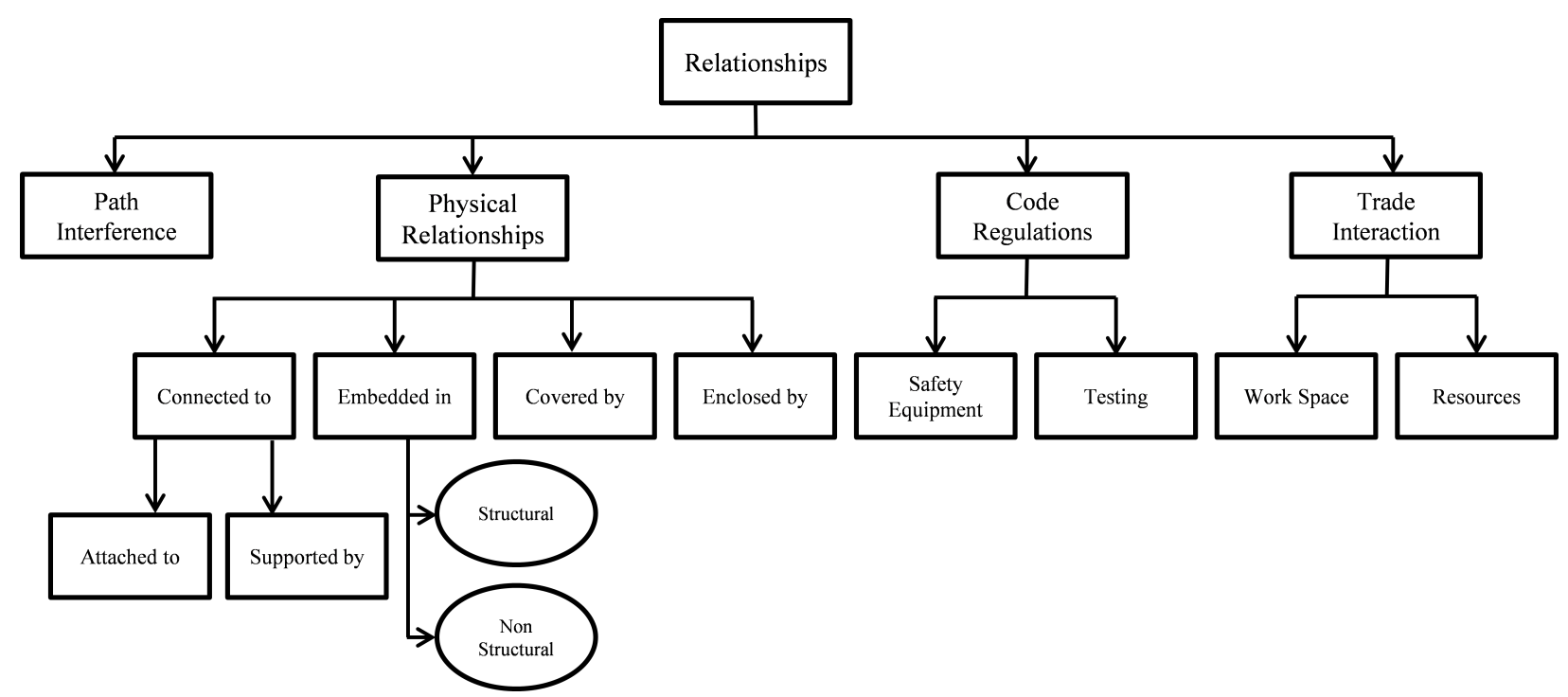

Figure 14: The proposed ontology to support automated progress monitoring 


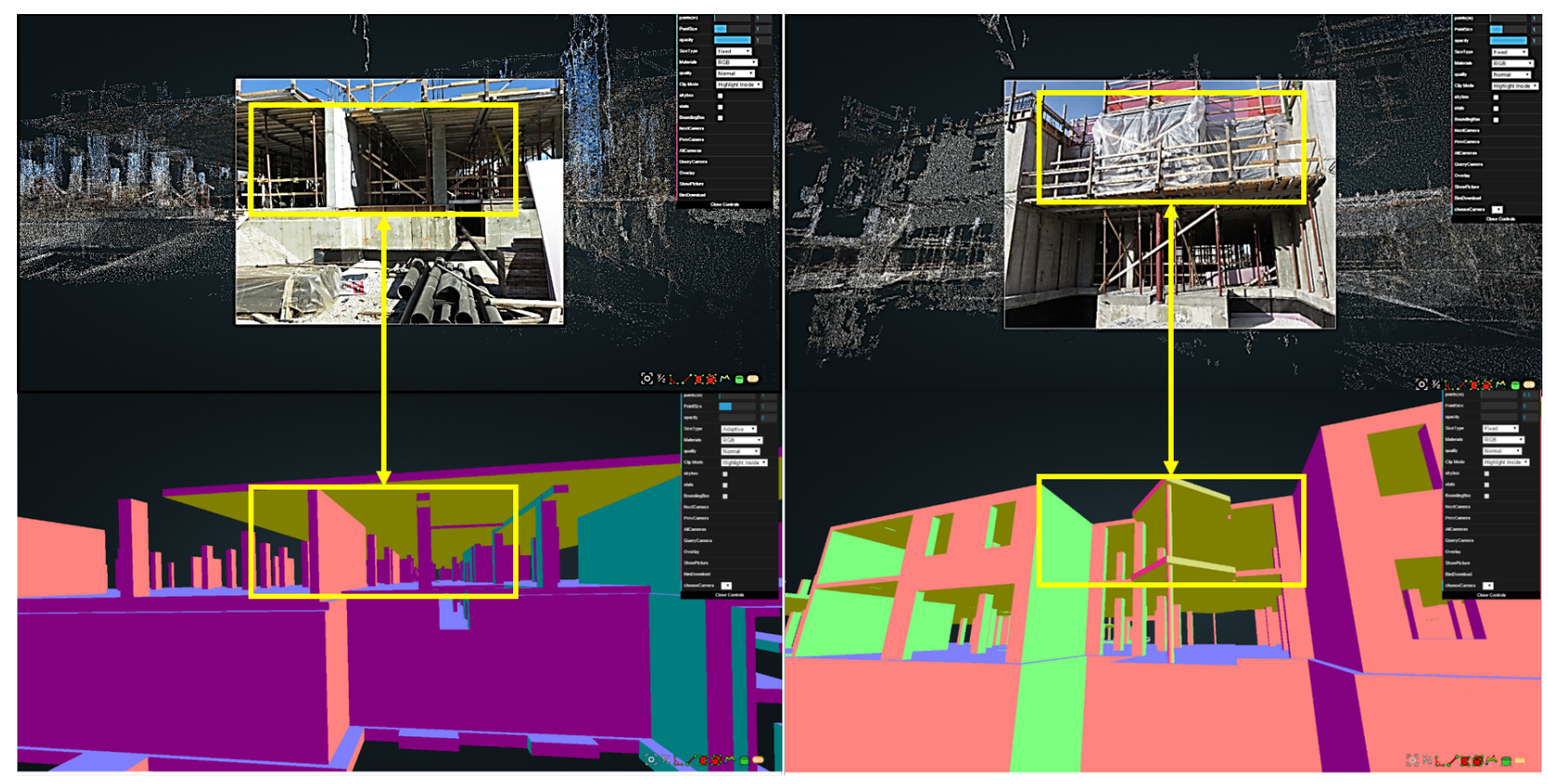

Figure 15: Point clouds with overlaid images and registered BIM illustrating limited visibilities: $R H_{O c t}$ (left) and $R H_{D e c}$ (right). 


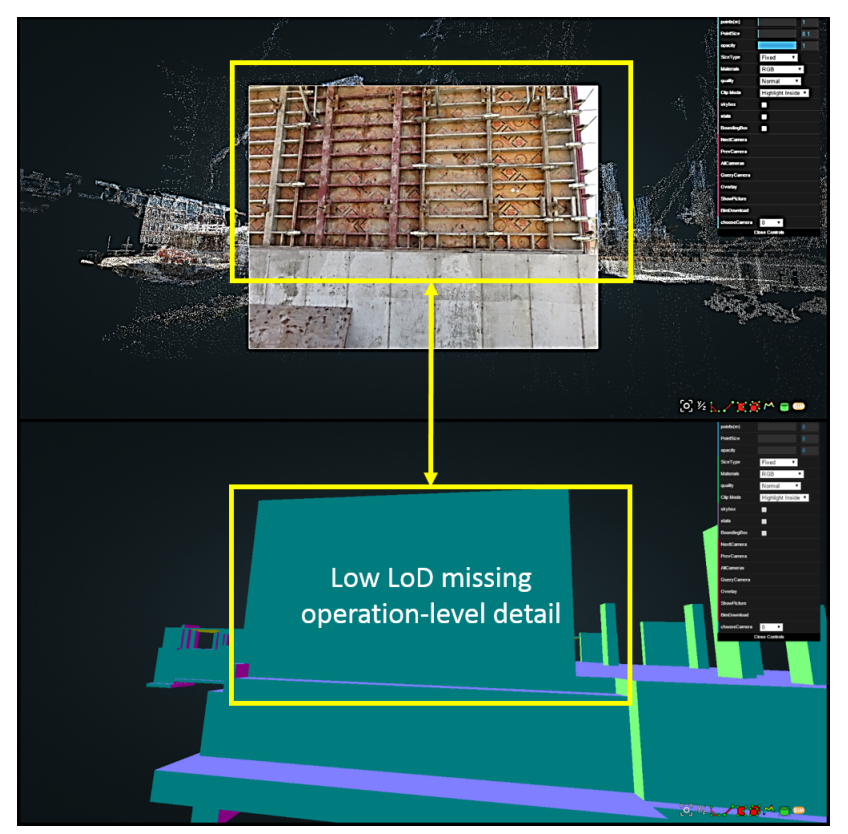

Figure 16: Low LoD in BIM: WIP concrete element shown in a point cloud+image and BIM 


\section{List of Tables}

Relationship ontology . . . . . . . . . . . . . . . . . .

2 Characteristics of professionals participating in the test and their current roles in their orga-

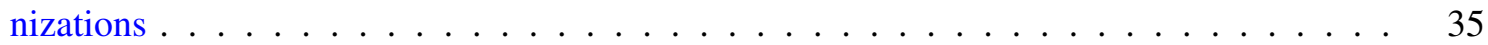
Section $\mathrm{A}$ of the user test on definition of physical relationships $\ldots \ldots \ldots \ldots \ldots \ldots$

4 Section B of the user test, focusing on application of the ontology on construction imagery (the italic part is the correct relationship which users were asked to fill in) . . . . . . . 40 The accuracy of results of the ontology class selection from questions on Section A . . . . 


\begin{tabular}{|l|l|l|}
\hline \multicolumn{1}{|c|}{ Relationship } & \multicolumn{1}{|c|}{ Example } \\
\hline Supported by & $\begin{array}{l}\text { Foundation wall supported } \\
\text { by concrete footing }\end{array}$ \\
\hline Attached to & $\begin{array}{l}\text { Electrical box connected to } \\
\text { foundation wall }\end{array}$ \\
\hline $\begin{array}{l}\text { Embedded in } \\
\text { (structural) }\end{array}$ & $\begin{array}{l}\text { Anchor bold embedded in } \\
\text { foundation wall }\end{array}$ \\
\hline $\begin{array}{l}\text { Embedded in } \\
\text { (non-structural) }\end{array}$ & $\begin{array}{l}\text { Conduit embedded in foun- } \\
\text { dation wall }\end{array}$ \\
\hline Enclosed by & MEP enclosed by first floor \\
\hline Covered by & $\begin{array}{l}\text { Foundation wall covered by } \\
\text { waterproofing }\end{array}$ \\
\hline
\end{tabular}

Table 1: Relationship ontology 


\begin{tabular}{|c|c|c|c|c|c|}
\hline \multirow{2}{*}{$\begin{array}{l}\text { Subject } \\
\text { Code }\end{array}$} & \multirow{2}{*}{$\begin{array}{c}\text { Types of Organization } \\
\text { Employed at }\end{array}$} & \multirow[t]{2}{*}{ Role in Organization } & \multirow{2}{*}{$\begin{array}{l}\text { Years in } \\
\text { the role }\end{array}$} & \multicolumn{2}{|c|}{ Test Scenario Used } \\
\hline & & & & Section A & Section B \\
\hline 1 & Academia & $\begin{array}{c}\text { Graduate Student } \\
\text { with Industry Experience }\end{array}$ & 5 & Yes & Yes \\
\hline 2 & Construction & Estimator & 7 & Yes & Yes \\
\hline 3 & Construction & Project Engineer & 5 & Yes & Yes \\
\hline 4 & Construction & Professor & 21 & Yes & Yes \\
\hline 5 & Construction & Project Director & 40 & Yes & Yes \\
\hline 6 & Construction & $\begin{array}{c}\text { Graduate Student } \\
\text { with Industry Experience }\end{array}$ & 10 & Yes & Yes \\
\hline 7 & Construction & Consultant & 10 & Yes & Yes \\
\hline 8 & Architecture & Executive Director & 35 & Yes & Yes \\
\hline 9 & Construction & MEP Coordinator & 7 & Yes & Yes \\
\hline 10 & Construction & Project Manager & 32 & Yes & Yes \\
\hline 11 & Architecture & Professor & 20 & Yes & Yes \\
\hline 12 & Construction & Professor & 15 & Yes & Yes \\
\hline 13 & Construction & Research Engineer & 32 & Yes & Yes \\
\hline 14 & Construction & $\begin{array}{c}\text { Graduate Student } \\
\text { with Industry Experience }\end{array}$ & 10 & Yes & Yes \\
\hline 15 & Construction & Construction Engineer & 3 & Yes & Yes \\
\hline 16 & Engineering/ Construction & Researcher & 10 & Yes & Yes \\
\hline 17 & Engineering & $\begin{array}{l}\text { Structural Engineer/ } \\
\text { Vice President }\end{array}$ & 32 & Yes & Yes \\
\hline 18 & Construction & Senior Vice President & 32 & Yes & Yes \\
\hline 19 & Construction & Professor & 25 & Yes & Yes \\
\hline 20 & Owner & Project Manager & 15 & Yes & Yes \\
\hline 21 & Construction & Formwork Design Engineer & 1 & Yes & Yes \\
\hline
\end{tabular}

Table 2: Characteristics of professionals participating in the test and their current roles in their organizations 


\begin{tabular}{|c|c|}
\hline The physical & The relationships between two building components \\
\hline $\begin{array}{l}\text { 1. Supported by } \\
\text { 2. Attached to } \\
\text { 3. Covered by } \\
\text { 4. Embedded in } \\
\text { 5. Enclosed by }\end{array}$ & 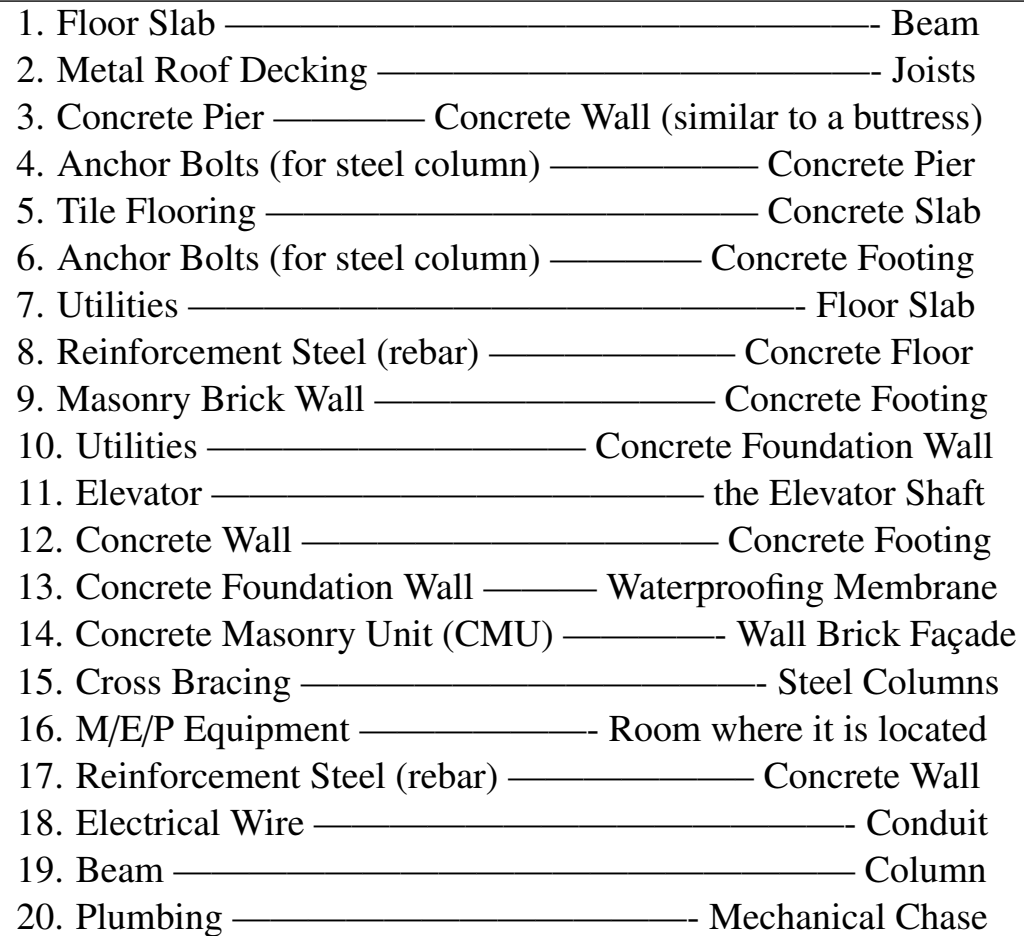 \\
\hline
\end{tabular}

Table 3: Section A of the user test on definition of physical relationships 


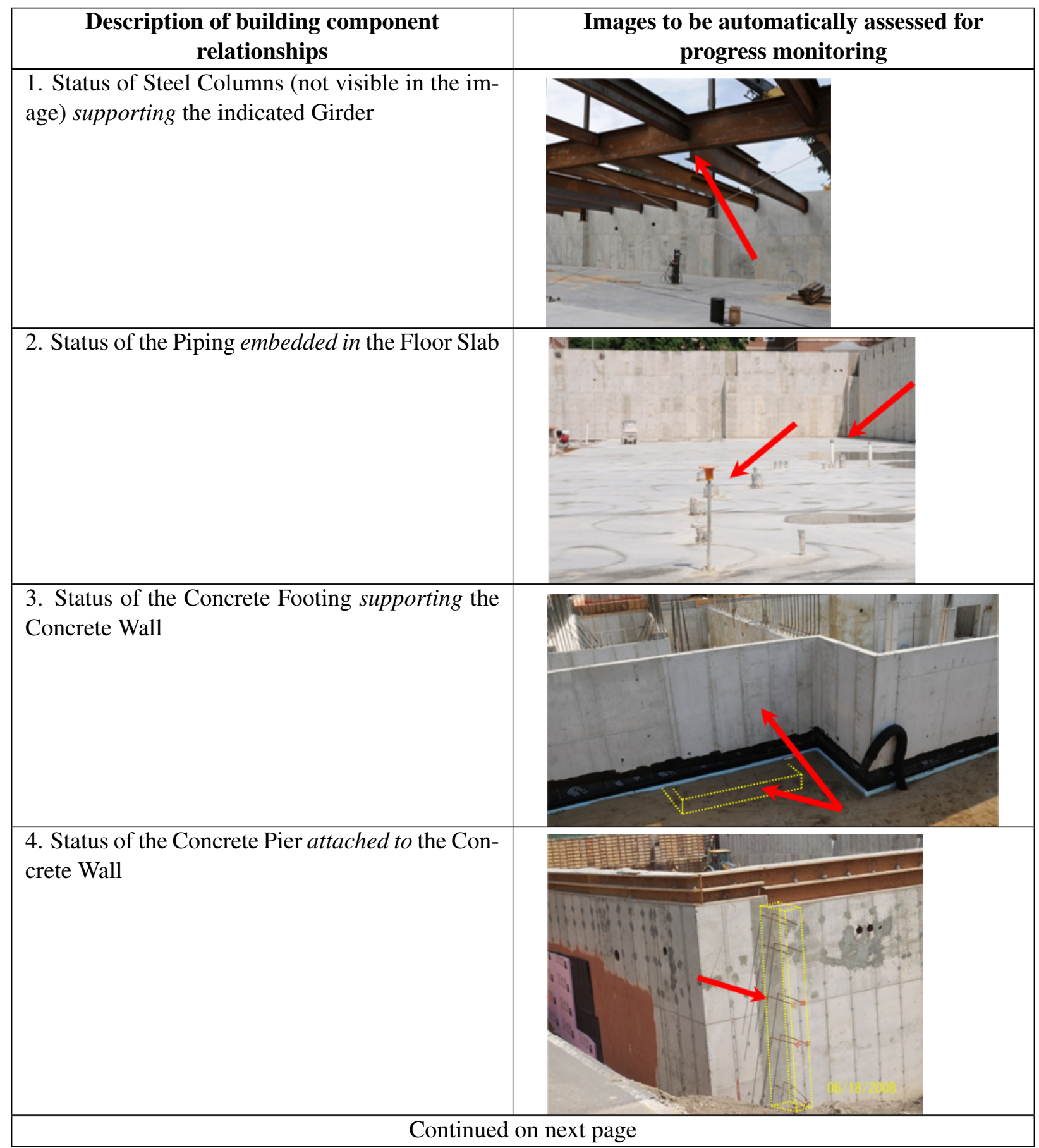


Table 4 - continued from previous page

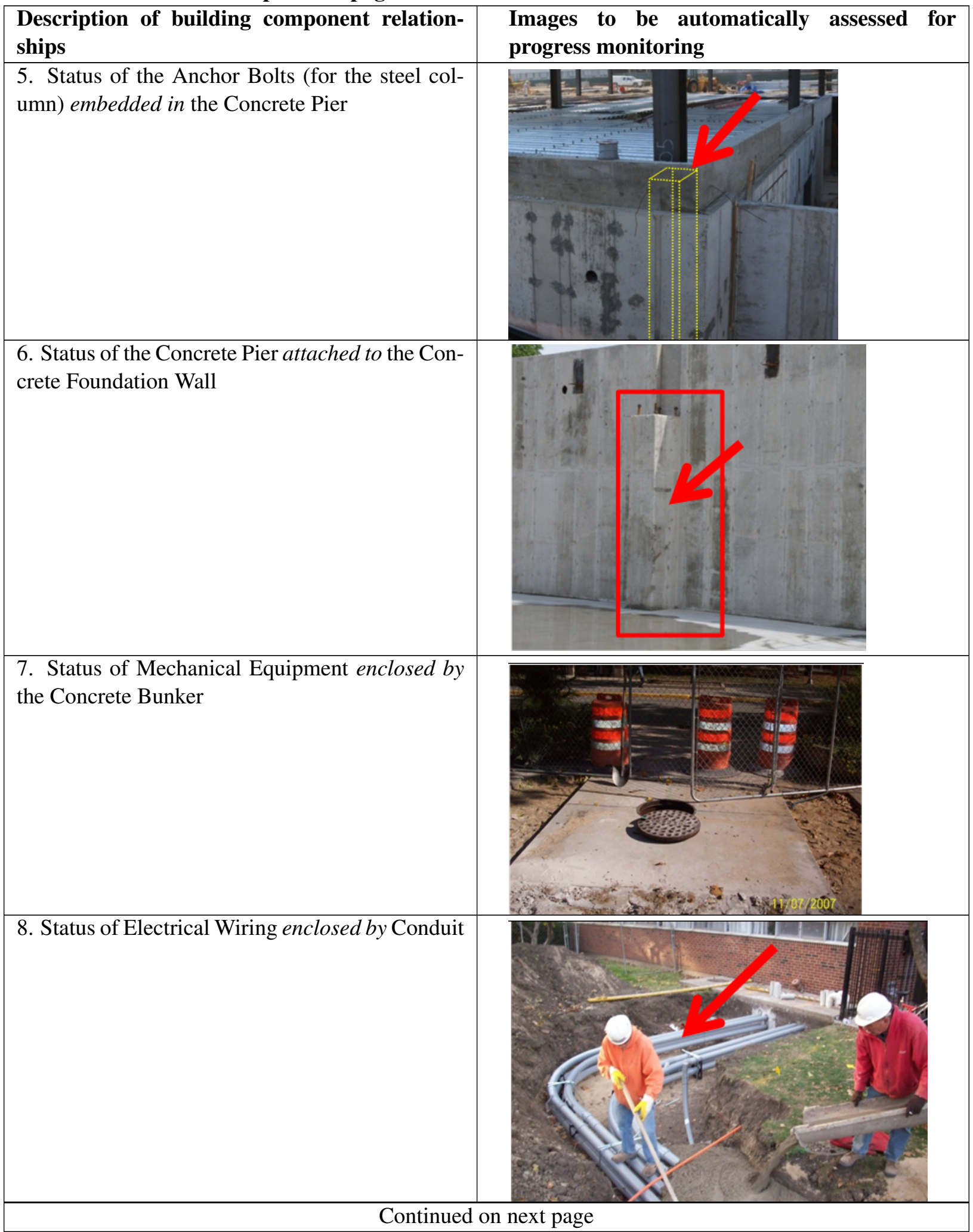


Table 4 - continued from previous page

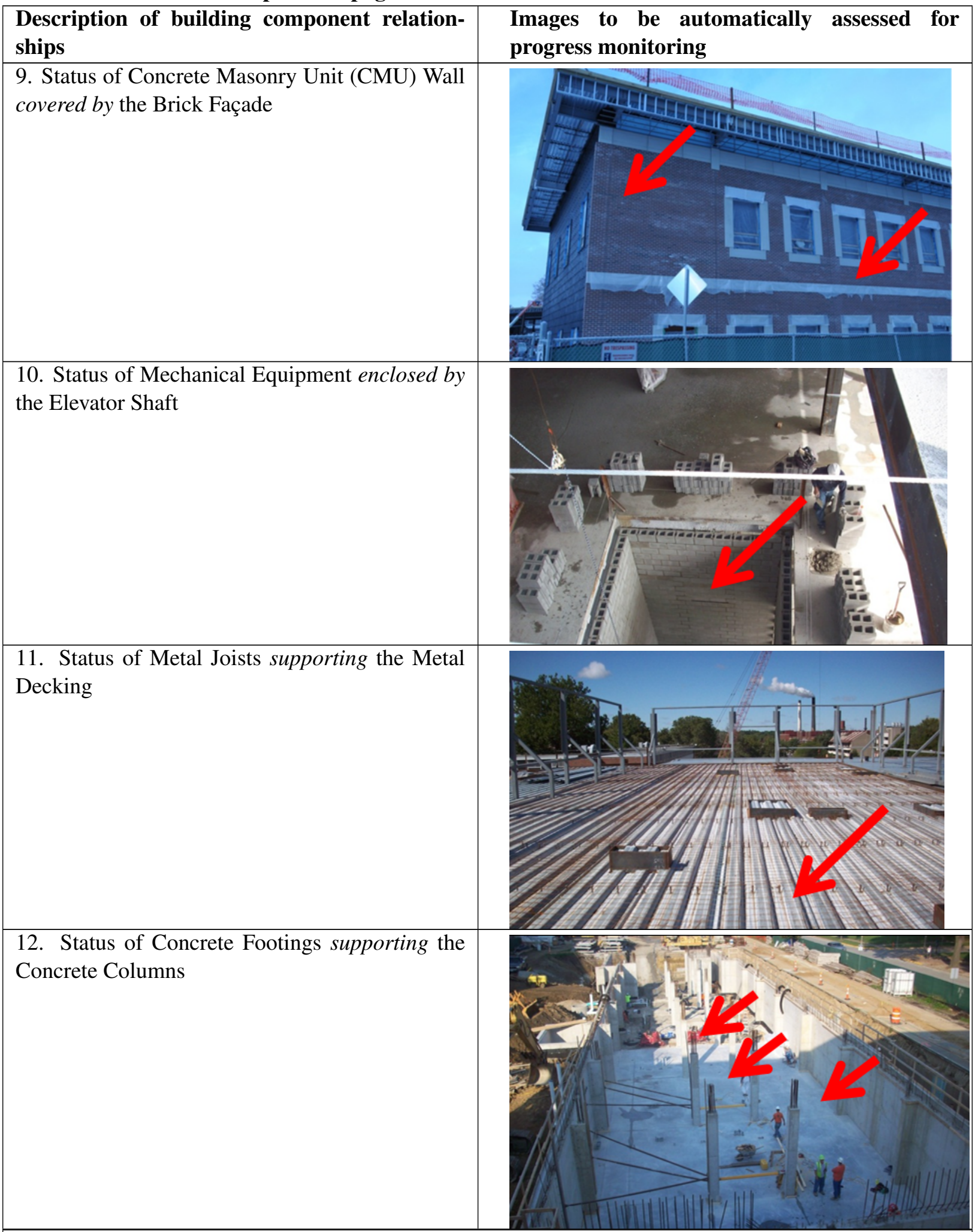

Continued on next page 
Table 4 - continued from previous page

\begin{tabular}{|l|l|}
\hline $\begin{array}{l}\text { Description of building component relation- } \\
\text { ships }\end{array}$ & $\begin{array}{l}\text { Images to be automatically assessed for } \\
\text { progress monitoring }\end{array}$ \\
Wall being placed & Status of Steel Rebar embedded in Concrete
\end{tabular}

Table 4: Section B of the user test, focusing on application of the ontology on construction imagery (the italic part is the correct relationship which users were asked to fill in) 


\begin{tabular}{|c|c|c|}
\hline Question & Ontology Class & Accuracy of the Response \\
\hline 1 & Supported by & $95 \%$ \\
\hline 2 & Supported by & $55 \%$ \\
\hline 3 & Attached to & $80 \%$ \\
\hline 4 & Embedded in-Structural & $75 \%$ \\
\hline 5 & Covered by & $55 \%$ \\
\hline 6 & Embedded in-Structural & $65 \%$ \\
\hline 7 & Embedded in-NonStructural & $70 \%$ \\
\hline 8 & Embedded in-Structural & $95 \%$ \\
\hline 9 & Supported by & $75 \%$ \\
\hline 10 & Embedded in-NonStructural & $65 \%$ \\
\hline 11 & Enclosed & $90 \%$ \\
\hline 12 & Supported by & $80 \%$ \\
\hline 13 & Covered by & $85 \%$ \\
\hline 14 & Covered by & $30 \%$ \\
\hline 15 & Attached to & $90 \%$ \\
\hline 16 & Enclosed by & $90 \%$ \\
\hline 17 & Embedded in-Structural & $95 \%$ \\
\hline 18 & Enclosed by & $80 \%$ \\
\hline 19 & Supported by & $80 \%$ \\
\hline 20 & Enclosed by & $75 \%$ \\
\hline
\end{tabular}

Table 5: The accuracy of results of the ontology class selection from questions on Section A 


\begin{tabular}{cccc}
\hline Dataset & \# of elements & \# of non-visible elements & $\%$ of possible enhancement \\
\hline$R H_{O c t}$ & 573 & 34 & $5.7 \%$ \\
\hline$R H_{\text {Dec }}$ & 705 & 53 & $7.5 \%$ \\
\hline
\end{tabular}

Table 6: Numbers of non-visible elements to total numbers of elements. 